Check for updates

Cite this: RSC Adv., 2017, 7, 35451

Received 2nd May 2017

Accepted 11th July 2017

DOI: $10.1039 / \mathrm{c} 7 \mathrm{ra04907b}$

rsc.li/rsc-advances

\section{One-step synthesis of magnetically recyclable Co@BN core-shell nanocatalysts for catalytic reduction of nitroarenes $\dagger$}

\begin{abstract}
Man Du, ${ }^{a}$ Qiuwen Liu, ${ }^{a}$ Caijin Huang (D) *a and Xiaoqing Qiu*b
We present a facile one-step synthesis of chemically stable and magnetic Co@BN core-shell nanoparticles. We found that Co@BN nanoparticles acted as excellent catalysts with high stability and magnetic recyclability for reduction of nitroarenes to aminoarenes under mild reaction conditions. The sample $13.6 \mathrm{wt} \%$ Co@BN showed the best catalytic activity for reduction of 4-nitrophenol (4-NP). In addition, a significant synergistic effect of the $\mathrm{h}-\mathrm{BN}$ support was observed during the catalytic reaction by effectively adsorbing/concentrating and ionizing the reactant nitroaromatics. Moreover, the kinetics of the catalytic reaction were investigated at different reaction temperatures, 4-nitrophenol concentrations, sodium borohydride concentrations, metal loadings and catalyst amounts. The activation energy of the catalytic reduction of 4-nitrophenol for $13.6 \mathrm{wt} \% \mathrm{Co}$ (aBN was determined to be $102.93 \mathrm{~kJ} \mathrm{~mol}^{-1}$. This work provides a clear example of Co@BN core-shell nanoparticles as nanocatalysts.
\end{abstract}

\section{Introduction}

In recent years, earth-abundant available transition metal nanoparticles have attracted growing attention in diverse fields of optics, ${ }^{1}$ magnetics ${ }^{2}$ and catalysis ${ }^{3}$ because of their excellent properties. Among these metals, cobalt is particularly interesting for its wide use as catalysts because of its loosely bonded d electrons and the resulting high electrical conductivity. ${ }^{4-7}$ Searching for larger surface-to-volume ratios and more active sites constitutes part of the driving force in developing nanoscale catalysts. However, for metal nanoparticles, they are inclined to aggregate in aqueous solution owing to surface hydrophobicity, ${ }^{8}$ resulting in eventual loss of catalytic activity. To solve this problem, extensive efforts have been devoted to stabilizing metal nanoparticles with various capping agents or supports. For instance, Crooks and co-workers demonstrated that metal nanoparticles can be effectively stabilized through macromolecular organic ligands. ${ }^{9}$ However, organic ligands can not be long-term stable in air, oxidizing solution or at high temperature. Another interesting stabilization strategy is to encapsulate nanoparticles with another material to form a coreshell hetero-structure. While core particles are wrapped with a shell, it causes changes in magnetic, electronic, optical,

${ }^{a}$ State Key Laboratory of Photocatalysis on Energy and Environment, College of Chemistry, Fuzhou University, Fuzhou 350002, P. R. China. E-mail: cjhuang@fzu. edu.cn

${ }^{b}$ College of Chemistry and Chemical Engineering, Central South University, Changsha, 41083, China.E-mail:xq-qiu@csu.edu.cn

$\dagger$ Electronic supplementary information (ESI) available. See DOI: $10.1039 / \mathrm{c} 7 \mathrm{ra} 04907 \mathrm{~b}$ catalytic and chemical properties compared with those of their individual components. ${ }^{10-13}$ Consequently, the core-shell structure has enabled a significant enhancement in photoluminescence, ${ }^{14-18}$ chemical and thermal stability, ${ }^{19}$ and processibility. ${ }^{20}$ Moreover, the shell also plays an important role in the core-shell structure to improve the photoluminescence quantum yield, ${ }^{15}$ exhibit high activity and selectivity in homogenous catalytic reaction, ${ }^{21}$ and enhance higher biocatalytic activity and temperature stability. ${ }^{22}$ Somorjai et al. demonstrated when Pt core is coated with a silica shell, it possesses excellent thermal stability and high catalytic performance for high-temperature reactions. ${ }^{23}$ Oelhafen et al. reported that the metallic Co core surround by oxide shell can avoid directly exposing to the air and have the property to exchange the magnetic system. ${ }^{24}$ The use of reduced graphene oxide ( $\mathrm{rGO}$ ) as a shell protects the core $\mathrm{Cu}$ nanoparticle from oxidation and the as-prepared $\mathrm{Cu} @ \mathrm{rGO}$ nanoparticles exhibit excellent catalytic performance towards the reduction of 4nitrophenol. ${ }^{25}$ Encouragingly, as an analogue to graphene, ${ }^{26}$ hexagonal boron nitride (h-BN) sheets have been used as a shell in our previous work to wrap $\mathrm{Cu}$ nanoparticles and the asobtained Cu@BN core-shell nanoparticles possesses good catalytic performance and high chemical stability. ${ }^{27}$

Two-dimensional (2D) h-BN material has attracted great interest owing to its nontoxicity, high surface area, appropriate chemical anchoring sites, chemical and thermal stability. ${ }^{28-30}$ Moreover, h-BN has been found to be an excellent support for functional materials to promote their (photo)-catalytic performance. ${ }^{31-33}$ Recently, Lei et al. showed that h-BN can serve as an excellent adsorbent material because of its good adsorption performance of organic compounds. ${ }^{30}$ For heterogeneous 
catalytic process, concentrating reactants (e.g. organic compounds) in the vicinity of the catalyst is beneficial for improving catalytic reaction rate. In this regard, h-BN was used in this work as a promising shell material to wrap/stabilize cobalt nanoparticles for catalyzing organic compounds.

Amino-aromatics are widely employed in dyes, pharmaceutical, polymers and herbicides. ${ }^{34-38}$ For example, 4-chloroaniline plays a significant role in the production of dyes. ${ }^{36}$ In addition, 4-aminophenol (4-AP) is an important intermediate in the preparation of analgesic and antipyretic drugs, ${ }^{39,40}$ and also used as a photographic developer, a corrosion inhibitor and an antioxidant. ${ }^{\mathbf{4 1 , 4 2}}$ Meanwhile, nitro-aromatics are considered to be over 500-fold more toxic than their corresponding aromatic amines. ${ }^{43}$ Therefore, conversion of nitro-aromatics to aminoaromatics is of great importance for the industrial production of amino compounds and industrial waste water treatment of nitro-compounds. The catalytic hydrogenation of nitroaromatics is an attractive conversion pathway and has been widely studied by using noble-metal based catalysts including $\mathrm{Ag}$ and $\mathrm{Au} .^{\mathbf{4 4 , 4 5}}$ In this paper, we report a new type of nanocomposite, composed of a magnetic metal core, Co, and an insulating shell, hexagonal boron nitride (h-BN). The asprepared Co@BN core-shell nanoparticles were introduced as catalysts for hydrogenation of nitroarenes (e.g. 4-nitrophenol, 4nitroaniline and 4-nitroanisole) to their corresponding aminoarenes. The experimental results showed that the assynthesized Co@BN nanoparticles acted as excellent catalysts with high durable stability for reduction of nitroarenes to aminoarenes under mild reaction conditions. The core-shell structure and magnetic property of Co core enabled easy separation from the reaction mixture. Moreover, effects of reactant concentration, metal loading, catalyst amount and reaction temperature on reaction rate and activation energy were studied as well.

\section{Experimental}

\subsection{Materials}

Boron oxide, urea and cobalt(II) nitrate were used as the raw materials in the preparation of Co@BN composites. Boron oxide was purchased from Aladdin Company. Cobalt(II) nitrate hexahydrate $\left(\mathrm{Co}\left(\mathrm{NO}_{3}\right)_{2} \cdot 6 \mathrm{H}_{2} \mathrm{O} \geq 47.8 \%\right)$ was used as cobalt precursor. Urea, 4-nitrophenol and sodium borohydride $\left(\mathrm{NaBH}_{4}\right)$ were obtained from Sinopharm Chemical Reagent Corporation. All other chemicals were of analytical grade and used without further purification. Deionized water was used throughout the study.

\subsection{Catalyst preparation}

The synthesis of Co@BN composites is indicated as follows: different amounts of cobalt nitrate $(0.09,0.9,1.8$ and $2.7 \mathrm{~g}$, respectively), $3 \mathrm{~g}$ of boron oxide and $6 \mathrm{~g}$ of urea were mixed in the mortar until it was ground into a fine powder. The resultant powder was placed in a tube furnace with sintering temperature at $1250{ }^{\circ} \mathrm{C}$ for $5 \mathrm{~h}$. The cobalt contents in Co@BN composites were detected by the Ultima2 ICP optical emission spectrometer. According to the corresponding cobalt contents, the samples were denoted as 0.94 wt $\%$ Co@BN, 8.3 wt $\%$ Co@BN, 13.6wt\% Co@BN and 20.0wt\% Co@BN, respectively. For contrast experiments, the sample cobalt without h-BN was prepared as the procedure mentioned above by placing $1.8 \mathrm{~g}$ cobalt nitrate in a tube furnace without adding boron oxide and urea.

\subsection{Catalyst characterization}

The crystal structure of the samples was recorded with an X-ray powder diffractometer (XRD, Bruker, D8 Advance, Cu-K $\alpha 1$ radiation). Fourier transformed infrared (FTIR) spectroscopy was conducted on a Nicolet Magna 670 Fourier transform infrared spectrometer at room temperature. Raman spectra were recorded by Raman spectrometer (Renishaw inVia Raman Microprobe) with an excitation source at $532 \mathrm{~nm}$. Transmission Electron Microscope (TEM) and selected-area electron diffraction (SAED) characterization were taken on TITAN G2 60-300 electron beam aberration corrected transmission electron microscope under an acceleration voltage of $300 \mathrm{kV}$. Magnetic hysteresis loops were measured on a Physical Property Measurement System (PPMS-9T, Quantum Design, USA). Nitrogen sorption measurements and pore size analysis were performed on a Micromeritics ASAP 2020 HD88 system. The sample was degassed at $180{ }^{\circ} \mathrm{C}$ for $8 \mathrm{~h}$ prior to the experiment. The electron paramagnetic resonance (EPR) spectra were observed by Bruker A300 spectrometer at room temperature.

\subsection{Catalytic activity measurements}

Considering the precision of the experiment, aqueous solutions of 4-nitrophenol and $\mathrm{NaBH}_{4}$ were freshly prepared prior to being used. Typically, $35 \mathrm{ml}$ of the deionized water, $4 \mathrm{ml}$ of nitroarenes (e.g. 4-nitrophenol) solution (100 ppm), $3 \mathrm{ml}$ of $\mathrm{NaBH}_{4}$ solution $\left(0.2 \mathrm{~mol} \mathrm{l}{ }^{-1}\right)$ and $10 \mathrm{mg}$ of the catalyst were added to a $100 \mathrm{ml}$ beaker with stirring. Every $2 \mathrm{~min}, 1.5 \mathrm{ml}$ of the reaction mixture was injected into a $2 \mathrm{ml}$ centrifuge tube immediately through a pressure syringe filter which can remove the catalyst from the reaction solution and end the reaction. The filtrated solution was then measured by using a conventional UV-visible spectrometer (Cary 50, VARIAN) using deionized water as a blank solution.

\section{Results and discussion}

\subsection{Structure characterization, morphology and magnetism}

Fig. 1 displays the XRD patterns of the as-obtained h-BN and Co@BN samples. The characteristic peaks of h-BN sample located at 26.7 and $42^{\circ}$ are assigned to the (002) and (100) crystalline facets, respectively (JCPDS card no. 45-0896). The diffraction peaks of Co@BN at around 44.2, 51.5 and $75.8^{\circ}$ correspond to the (111), (200) and (220) planes of the cubic phase cobalt, respectively (JCPDS card no. 15-0806). Moreover, the intensity of the peak at $44.2^{\circ}$ for cobalt increases with increasing amount of the cobalt content. For the Co@BN samples, the diffraction peaks of h-BN are similar to that of the pure phase boron nitride, indicating that the crystal structure of 




Fig. 1 XRD patterns of $h-B N$ and the Co@BN samples with various $C o$ loadings.

boron nitride has not changed when boron nitride and cobalt are combined. No diffraction peaks originating from cobalt oxides were observed under the detection limit and sensibility of the XRD apparatus.

FTIR was performed to identify functional groups existed in the samples (Fig. S1a $\uparrow$ ). The peaks located at 786 and $1387 \mathrm{~cm}^{-1}$ are attributed to the out-of-plane $\mathrm{B}-\mathrm{N}-\mathrm{B}$ bending vibration $\left(\mathrm{A}_{2 \mathrm{u}}\right)$ and the in-plane $B-N$ transverse stretching vibration $\left(E_{1 u}\right)$, respectively. ${ }^{46,47}$ There are no obvious peaks corresponding to cobalt oxides, such as $\mathrm{CoO}$ and $\mathrm{Co}_{3} \mathrm{O}_{4}$ which are featured by a broad infrared band around 510 and $500 \mathrm{~cm}^{-1}$, respectively. ${ }^{48}$ Dopant incorporation, defects, and lattice disorder in a host lattice can be detected by analyzing Raman spectra. ${ }^{49}$ Fig. S1b $\dagger$ gives the Raman spectra of the Co@BN samples with various cobalt contents. The spectral position located at $1368 \mathrm{~cm}^{-1}$ belongs to the characteristics of the high frequency vibration Raman peaks $\left(\mathrm{E}_{2 \mathrm{~g}}\right)$ between boron nitride layers. ${ }^{50-52}$ Besides, it is noteworthy that there are no Raman signals from $\mathrm{Co}_{3} \mathrm{O}_{4}(472$ $\mathrm{cm}^{-1}\left(\mathrm{E}_{\mathrm{g}}\right), 507 \mathrm{~cm}^{-1}\left(\mathrm{~F}_{2 \mathrm{~g}}\right)$ and $\left.662 \mathrm{~cm}^{-1}\left(\mathrm{~A}_{1 \mathrm{~g}}\right)\right)^{53}$ and $\mathrm{CoO}(1000-$ $\left.1100 \mathrm{~cm}^{-1}\right){ }^{48}$ This indicates that the Co@BN samples do not contain detectable cobalt oxide, which is in good accordance with the results of XRD and FTIR analysis.

Fig. 2 shows the as-synthesized Co@BN nanoparticles with a core-shell structure. For the sample $13.6 \mathrm{wt} \%$ Co@BN, it has a particle size of $c a$. 100-200 nm in diameter and a shell of 30$50 \mathrm{~nm}$ in thickness (Fig. 2a and b). Moreover, the highresolution TEM (HRTEM) image (Fig. 2c) displays the lattice fringes corresponding to the (002) plane of h-BN and the (111) plane of cubic metallic cobalt, respectively. Fig. $2 \mathrm{~d}$ presents the selected-area electron diffraction (SAED) patterns indexed to (111), (200), and (220) of cubic cobalt, which is in agreement with the XRD results. Meanwhile, Fig. $2 \mathrm{~d}$ also demonstrates that the as-formed cobalt core is single crystalline. ${ }^{54}$ The nanoflake shell shows a polycrystalline SAED pattern corresponding to the hexagonal BN phase. ${ }^{55}$

The magnetization curve displays that Co@BN nanoparticles are superparamagnetic ${ }^{56,57}$ at $300 \mathrm{~K}$ (Fig. S2a $\dagger$ ). The saturation magnetization $\left(M_{\mathrm{s}}\right)$ value was determined to be $21.27 \mathrm{emu} \mathrm{g}^{-1}$ from the hysteresis loops of Co@BN. We also found that Co@BN nanoparticles can be easily dispersed in a post-reaction solution (see catalytic activity test for details) and quickly collected by a magnet (Fig. S2b†), which is beneficial for its recovery and reuse for application in heterogeneous catalysis.
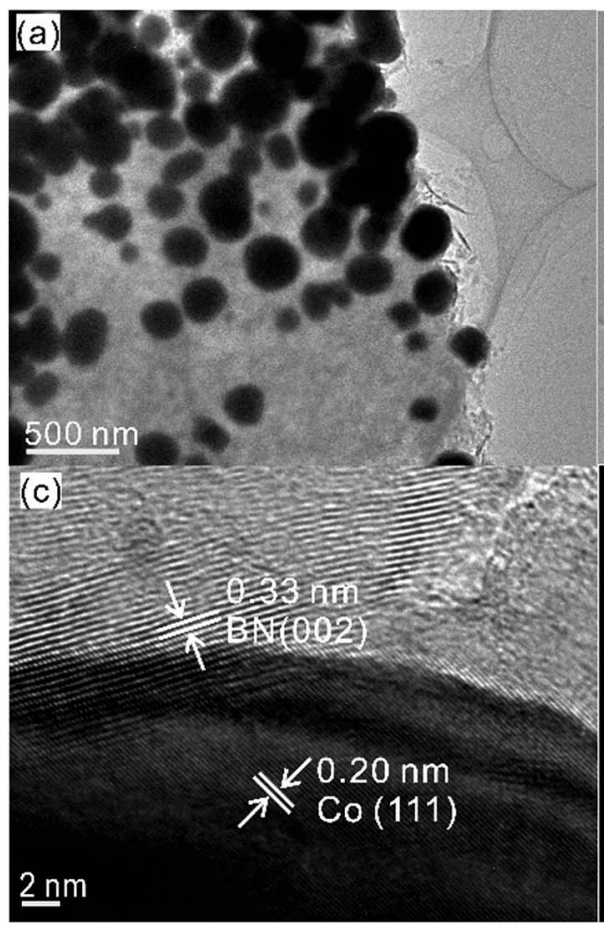
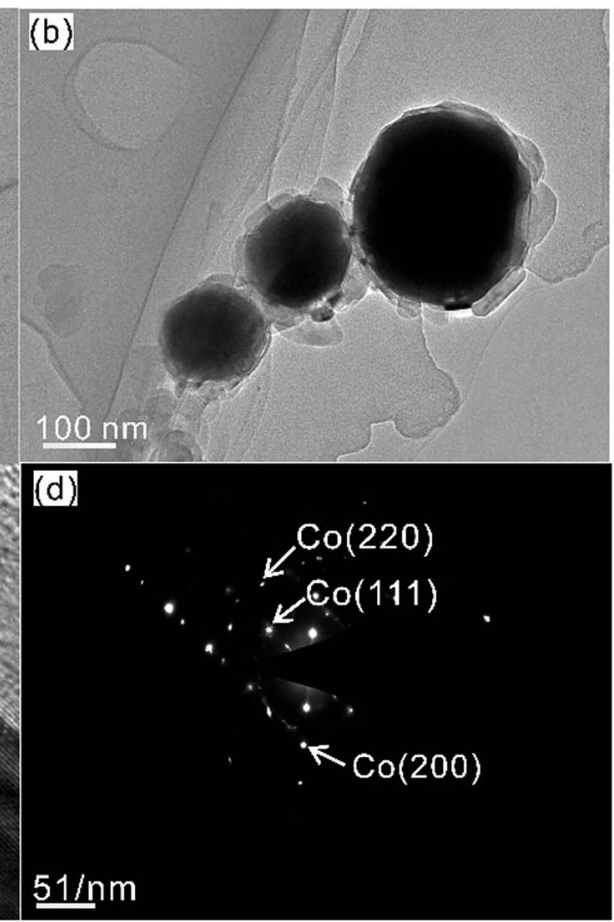

Fig. 2 (a, b) TEM and (c) HRTEM images of 13.6 wt\% Co@BN. (d) The SAED pattern of 13.6 wt\% Co@BN. 


\subsection{Catalytic activity of Co@BN}

The catalytic performance of the as-prepared samples was evaluated through catalytic hydrogenation of nitroarenes (e.g. 4nitrophenol). The reduction of 4-nitrophenol by excess $\mathrm{NaBH}_{4}$ follows the equation under alkaline conditions indicated as follows:

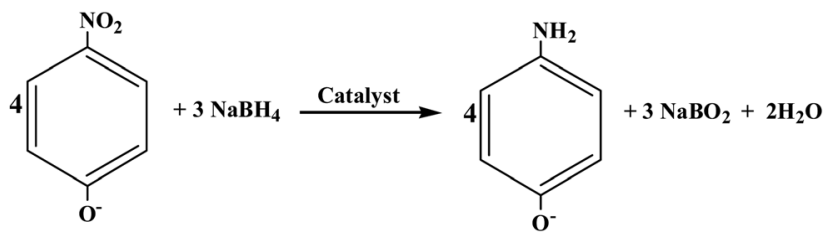

This reaction can be easily monitored by UV-visible spectroscopy. Normally, 4-nitrophenol has a typical absorption peak at $317 \mathrm{~nm}$ (Fig. S3†). However, after adding $\mathrm{NaBH}_{4}$ solution, a red shift of the maximum absorption peak occurs from $317 \mathrm{~nm}$ to $400 \mathrm{~nm}$ immediately and its color accordingly altered from light yellow to deep yellow, which is attributed to the formation of 4-nitrophenolate ions under alkaline conditions. ${ }^{58}$ Therefore, we monitored the concentration of 4-nitrophenol through the absorbance at $400 \mathrm{~nm}$. Interestingly, when h-BN was mixed with 4-nitrophenol, the absorbance at $400 \mathrm{~nm}$ had a slight increase, suggesting that the support h-BN can function as a weak base to ionize a part of 4-nitrophenol. Fig. 3a shows the time course of catalytic reduction of 4-nitrophenol by $\mathrm{NaBH}_{4}$ over $13.63 \mathrm{wt} \%$ Co@BN composites. Decrease in the absorbance of the peak at $400 \mathrm{~nm}$ with reaction time means the conversion of 4-nitrophenol. Moreover, two isosbestic points are observed at $277 \mathrm{~nm}$ and $312 \mathrm{~nm}$, suggesting that the 4nitrophenol were quickly converted to 4-aminophenol without any byproducts. ${ }^{59}$ Complete conversion of 4-nitrophenol to 4aminophenol was achieved within $22 \mathrm{~min}$. The yield and selectivity were $96 \%$ and $99 \%$, respectively. The total turnover number (TON) of $13.63 \mathrm{wt} \%$ Co@BN was 5, which is higher than some cobalt-based catalysts reported in the literature (Table $\mathrm{S} 1 \dagger)$. These results suggest that Co@BN nanoparticles exhibited a good catalytic activity.

To further explore the catalytic behavior of the Co@BN samples, comparative experiments and kinetics on the conversion of 4-nitrophenol to 4-aminophenol were investigated. According to Lambert-Beer's law, the ratio of the concentration of 4-nitrophenol at any time $\left(C_{t}\right)$ and the initial concentration of 4-nitrophenol $\left(C_{0}\right)$, namely $C_{t} / C_{0}$, can be determined by the ratio of the corresponding absorbance $\left(A_{t} / A_{0}\right)$. Fig. $3 \mathrm{~b}$ describes the time course of $C_{t} / C_{0}$ for the as-prepared catalysts, which reflects the catalytic activity of the catalysts used. 0.94 wt\% Co@BN, h$\mathrm{BN}$ and bare cobalt were only slightly active with a slow reduction of 4-nitrophenol. Obviously, 13.6 wt\% Co@BN possesses the highest catalytic activity among the samples. Moreover, since the concentration of $\mathrm{NaBH}_{4}$ is generally much higher than that of 4-nitrophenol $\left(\left[\mathrm{NaBH}_{4}\right] /[4-\mathrm{NP}]=205: 1\right)$, this reduction reaction (eqn (1)) can be considered as a pseudo-first-order reaction. ${ }^{59}$ Fig. $3 \mathrm{c}$ represents plots of $\ln \left(C_{t} / C_{0}\right)$ versus relevant
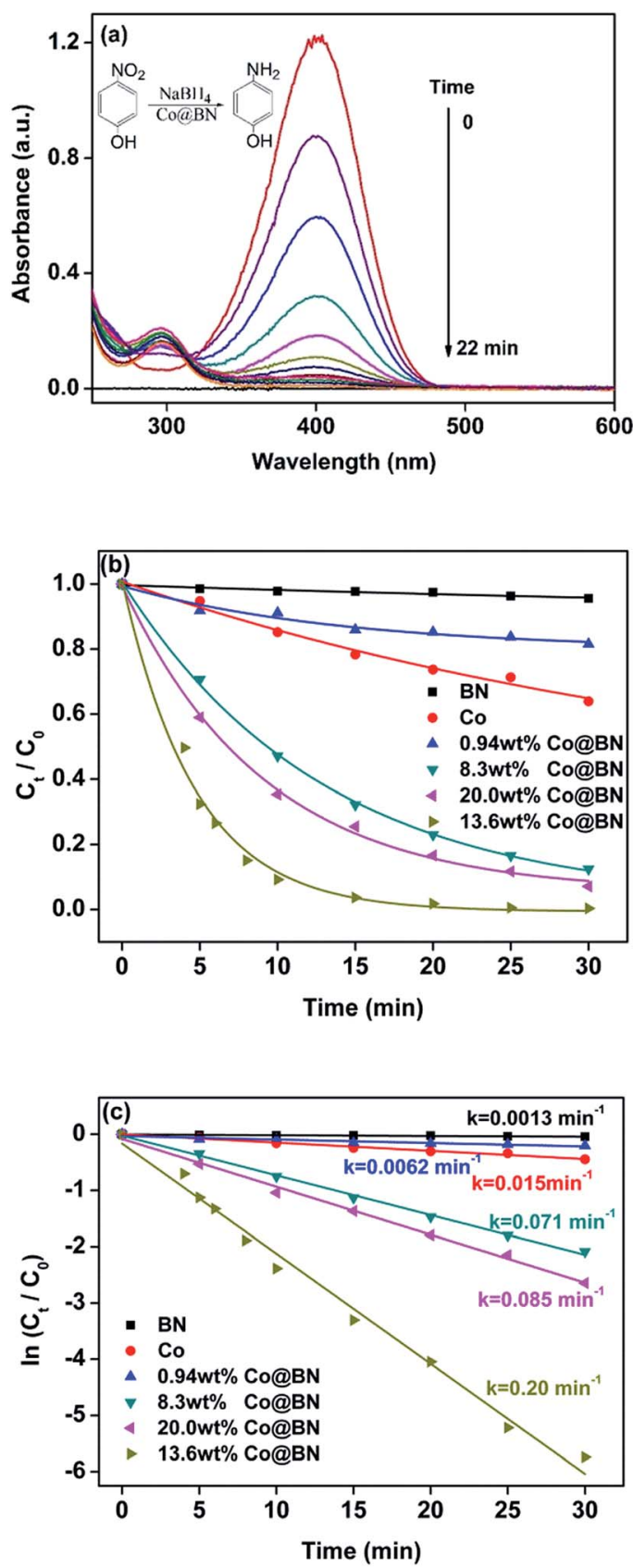

Fig. 3 (a) Catalytic reduction of 4-NP in the presence of $\mathrm{NaBH}_{4}$ by 13.63 wt\% Co@BN nanocatalysts. (b) Variation of $C_{t} / C_{0}$ versus reaction time for the reduction of 4-NP with different catalysts. (c) Rate constants of the catalytic reduction reaction of 4-NP obtained with different catalysts through a plot of $\ln \left(C_{t} / C_{0}\right)$ versus time $(T=288 \mathrm{~K})$.

reaction time for the catalysts. As can be seen, the linear relationship between $\ln \left(C_{t} / C_{0}\right)$ and the corresponding reaction time confirms that pseudo-first-order kinetics is available for this reaction. According to the first order kinetic equation: $\ln \left(C_{t} / C_{0}\right)$ $=-k t$, the rate constant $k$ can be directly achieved by using absolute values of the slope of the linear plots. It is clear that among the samples, the catalyst 13.6 wt\% Co@BN has the highest rate constant $0.20 \mathrm{~min}^{-1}$, and was chosen as a model catalyst in this study. 
Furthermore, we also investigated catalytic reduction of other nitroarenes including 4-nitroaniline, 4-nitrochlorobenzene, 4-nitromethylbenzene and 4-nitroanisole under the same reaction condition. Fig. 4 gives conversion of these nitroarenes within $30 \mathrm{~min}$ in the presence of excess $\mathrm{NaBH}_{4}$ using the catalyst $13.6 \mathrm{wt} \% \mathrm{Co@BN}$. The conversion reaches about $100 \%$ for 4-nitroaniline, 4-nitrophenol and 4-nitroanisole, while about 82 and $74 \%$ for 4-nitrochlorobenzene and 4-nitromethylbenzene, respectively. This is likely due to substituent effect from different functional groups (e.g. hydroxyl, methyl) for nitroarenes. ${ }^{60-62}$ Among these reactants, nitroarenes with electron-donating groups (e.g. $p$-OH, $p-\mathrm{NH}_{2}, p$ $\left.\mathrm{OCH}_{3}\right)$ appears to be more easily reduced than those with electron-withdrawing groups (e.g. $p$-Cl) ${ }^{60-62}$ while for hydrophobic 4-methylnitrobenzene poor water-solubility restricts its reaction activity. ${ }^{61}$ The results also suggest that the Co@BN nanocatalysts possess excellent catalytic activity for the hydrogenation of nitroarenes with different substituent groups.

\subsection{Kinetic study}

For this reduction reaction (eqn (1)), the standard reduction potential for 4-NP/4-AP and $\mathrm{H}_{3} \mathrm{BO}_{3} / \mathrm{BH}_{4}{ }^{-}$are -0.76 and $-1.33 \mathrm{~V}$ versus normal hydrogen electrode (NHE), respectively. ${ }^{\mathbf{5 8 , 6 3}}$ That is to say, this reaction is a thermodynamically feasible process as indicated by eqn (1). Nevertheless, it is difficult for this reaction to spontaneously proceed without catalysts (Fig. S4†) due to a high activation energy. ${ }^{58}$ Fig. 5 presents kinetic study on the reduction of 4-nitrophenol to 4-aminophenol catalyzed by 13.6 wt\% Co@BN at various temperatures: $15,20,25$ and $30{ }^{\circ} \mathrm{C}$. The relevant linear relationships between $\ln \left(C_{t} / C_{0}\right)$ and the corresponding reaction time are shown in Fig. 5a. It is clear that the reaction rate is quite sensitive to temperature and the value of rate constant $k$ increases with the temperature conducted. In addition, according to the Arrhenius equation: $\ln k=\ln A-\frac{E_{\mathrm{a}}}{R T}$, the activation energy $\left(E_{\mathrm{a}}\right)$ can be obtained from the slope on the basis of the linear fitting of $\ln k$ versus $1000 / T$. The activation energy of the reaction catalyzed by 13.6

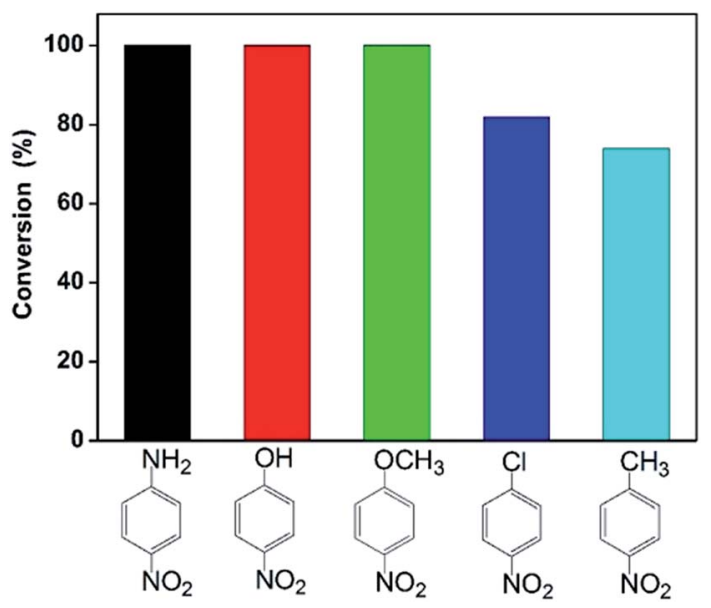

Fig. 4 Conversion of nitroaromatic compounds with 13.6 wt\% Co@BN under the same condition.
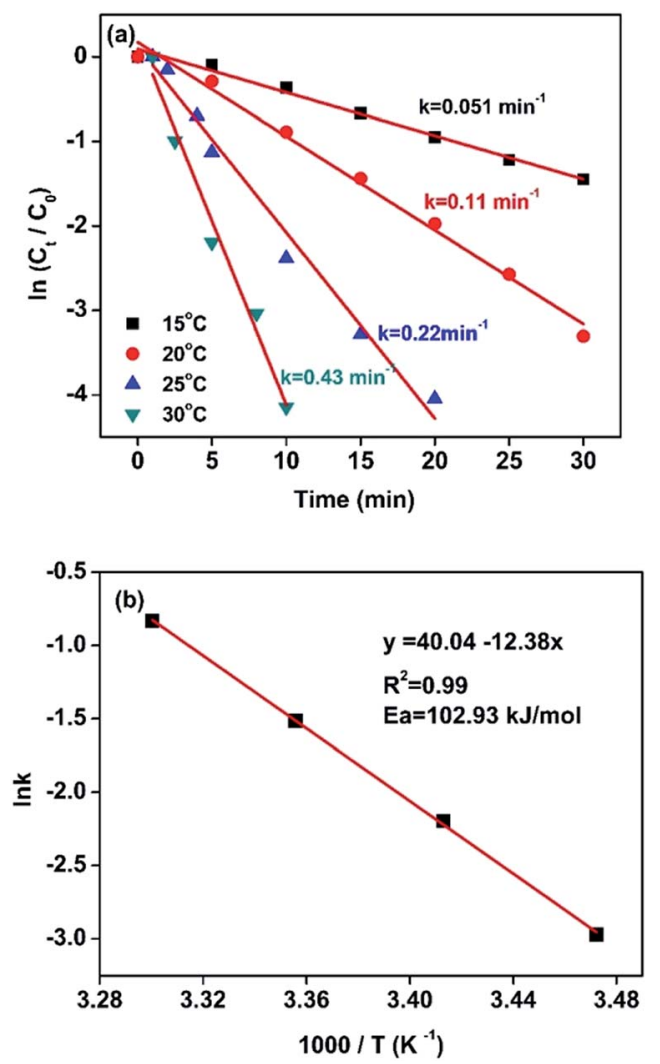

Fig. 5 (a) Plot of $\ln \left(C_{t} / C_{0}\right)$ versus time for the reduction of 4-nitrophenol over 13.63 wt\% Co@BN at different temperatures. Reaction conditions: $10 \mathrm{mg}$ of the catalyst; $2 \mathrm{ml}$ of $\mathrm{NaBH}_{4}(0.2 \mathrm{M})$ and $4 \mathrm{ml}$ of 4 nitrophenol (100 ppm). (b) The corresponding Arrhenius plot.

wt\% Co@BN was determined to be $102.93 \mathrm{~kJ} \mathrm{~mol}^{-1}$ from the Arrhenius plot (Fig. 5b).

As seen in eqn (1), the concentration of sodium hydroxide and 4-nitrophenol and catalyst amount play an important role on the catalytic reaction. Fig. 6a shows the effect of 4-nitrophenol at initial concentrations of 50, 100 and $200 \mathrm{ppm}$ on reaction kinetics, while keeping the $\mathrm{NaBH}_{4}$ concentration constant at $0.2 \mathrm{M}$ and the amount of catalyst at $10 \mathrm{mg}$. The rate constant $k$ was found to decrease with increasing the concentration of 4-nitrophenol. This kind of phenomenon seems abnormal, Xia et al. explained that a high concentration of 4nitrophenol may cover almost the entire surface of the catalyst, which limits electron transfer from $\mathrm{NaBH}_{4}$ to 4-nitrophenol and thus hinders the catalytic action of $\mathrm{NaBH}_{4} \cdot{ }^{64}$ The slope of the line given in the insert of Fig. $6 \mathrm{a}, 0.98 \approx 1$, suggests that the reaction is first order with respect to the 4-nitrophenol concentration. ${ }^{65,66}$ Fig. $6 \mathrm{~b}$ presents the effect of the $\mathrm{NaBH}_{4}$ concentration $(0.1,0.15,0.2$ and $0.3 \mathrm{M})$ on the reduction of 4 nitrophenol. 4-Aminophenol generation rate is improved with the increment of the concentration of $\mathrm{NaBH}_{4}$. The plot of $\ln k v s$. $\ln \left[\mathrm{NaBH}_{4}\right]$ gives a straight line with a slope of $0.97 \approx 1$, meaning that the catalytic reaction is first order with respect to the $\mathrm{NaBH}_{4}$ concentration (Fig. 6b inset). Fig. 6c reveals an effect of catalyst dosage on 4-aminophenol generation rate. We can see that the 4-aminophenol generation rate increases with the 

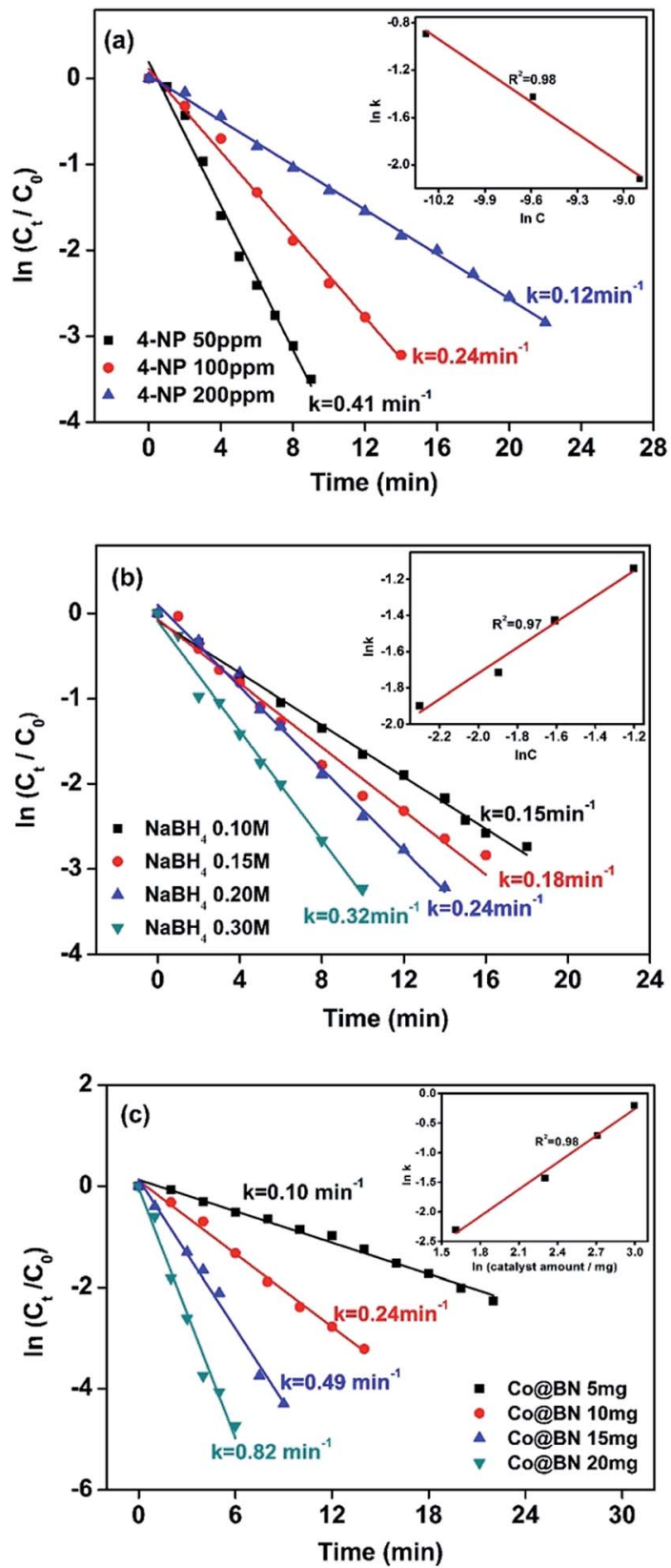

Fig. 6 Plots of $\ln \left(C_{t} / C_{0}\right)$ versus time for the reduction of 4-NP with different concentrations of (a) 4-NP, (b) $\mathrm{NaBH}_{4}$ and (c) dosage of 13.6 wt\% Co@BN. The inset of each figure shows the plot of 4-AP generation rate vs. the concentration of $4-\mathrm{NP}, \mathrm{NaBH}_{4}$ and cobalt (both in logarithmic scale), respectively (see text for details).

amount of catalyst. Moreover, the slope of the plot of $\ln k v s$. $\ln$ (catalyst amount) is 0.98 , which is approximately equal to 1 (Fig. 6c insert). Therefore, the reduction of 4-NP is first order with respect to the amount of Co@BN catalyst.

\subsection{Stability and recycle of Co@BN}

Stability or recycling ability is of great importance to the performance of catalysts. The recycling experiment for $13.6 \mathrm{wt} \%$ Co@BN was carried out by repeating the reduction process for five cycles (Fig. 7). Successive UV-vis spectra for the reduction reaction of 4-nitrophenol in each catalysis recycle given in Fig. S5. $\dagger$ Furthermore, we have detected the load of Co on the recycled catalyst by inductive coupled plasma emission spectrometer (Table S2 $\dagger$ ). A slight weight loss in cobalt load in Co@BN catalysts ranges from $13.6 \%$ (before catalysis) and 11.5\% (after five catalysis cycles). Considering detecting deviation $(\sim 2 \%)$ for this measurement, we believe that Co nanostructures are relatively stable during the reduction reactions. The recycle experiments showed that the as-prepared Co@BN nanocatalyst has an excellent catalytic stability. Moreover, by comparing the XRD patterns of the catalyst before and after the reaction (Fig. S6†), there is no obvious change in diffraction peaks, confirming the structure stability of the catalyst during the reaction.

\subsection{Adsorption of h-BN}

High surface area, thermal and chemical stability makes h-BN become an ideal candidate as an absorbent material, ${ }^{30}$ which is helpful for heterogeneous catalysis. In this regard, the specific surface area and pore size distribution of $13.6 \mathrm{wt} \%$ Co@BN were analyzed using $\mathrm{N}_{2}$ adsorption and desorption isotherms, respectively (Fig. S7†). The Co@BN sample displayed typical type IV adsorption isotherms with an H3-type hysteresis loop. ${ }^{67} \mathrm{Co@BN} \mathrm{had} \mathrm{BET-specific} \mathrm{surface} \mathrm{areas} \mathrm{of} \mathrm{approximately}$ $46.6 \mathrm{~m}^{2} \mathrm{~g}^{-1}$. The pore size distribution (calculated via the $\mathrm{BJH}$ method) shows that the pore size of Co@BN is centered at around $13.2 \mathrm{~nm}$ (Fig. S7b †). This suggests a mesoporous structure characteristic of the Co@BN. Meanwhile, the mesoporous size distribution is a relatively wide which is beneficial for improving the adsorption of the reactants. Meanwhile, the absorption performance of BN on 4-nitrophenol solutions with consecration of 50, 100 and $200 \mathrm{ppm}$ were explored. Fig. S8a $\dagger$ describes the absorbance change of 4-nitrophenol (100 ppm) at $317 \mathrm{~nm}$ over time in the presence of h-BN. After dispersing $10 \mathrm{mg}$ of h-BN powder into 4-nitrophenol solutions with stirring, the absorbance at $317 \mathrm{~nm}$ quickly decreased to a much lower constant value within $2 \mathrm{~min}$. Moreover, for the 4-nitrophenol solutions of $50 \mathrm{ppm}$ and $200 \mathrm{ppm}$, the absorption

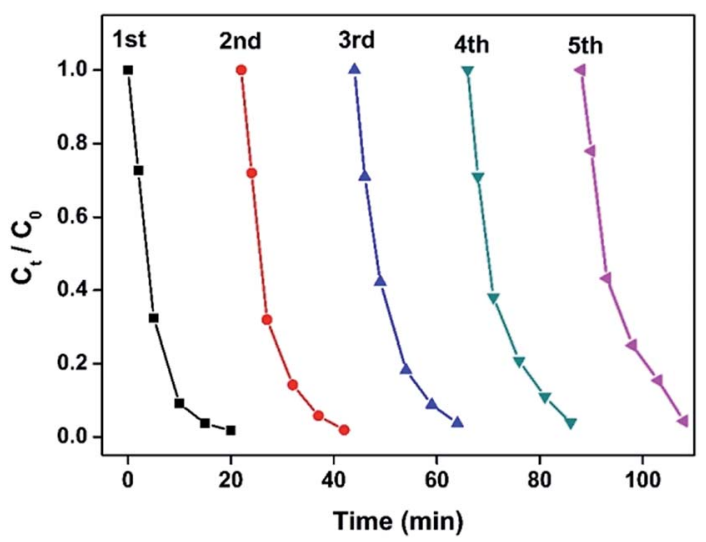

Fig. 7 Plots of $C_{t} / C_{0}$ versus time for the reduction of 4-NP catalyzed by the as-prepared $13.6 \mathrm{wt} \%$ Co@BN catalyst ([4-NP] $=100 \mathrm{ppm})$. The catalyst was repeatedly used for five cycles. 
approaches saturation in nearly $3 \mathrm{~min}$ and $1 \mathrm{~min}$, respectively (Fig. S8b and $\mathrm{c} \dagger$ ). Through quick absorption of 4-nitrophenol, a high local concentration of 4-nitrophenol occurs on the surface of h-BN and at the vicinity of the catalyst. This is beneficial to accelerate the reaction rate.

\subsection{Approaching to the mechanism}

To get more insights into the reaction process, the EPR experiment was conducted at room temperature using a spin trapper DMPO. Results obtained from spin trapping experiments are displayed in Fig. S9. $\dagger$ It is clear that spectra (b) and (c) originate from the formation of $\mathrm{H}^{\cdot}$ radical adducts (DMPO-H, $\left.a_{\mathrm{N}}=16.6 \mathrm{G}, a_{\mathrm{H}}=22.5 \mathrm{G}\right)^{68}$ for the solution containing and (b) DMPO, $\mathrm{NaBH}_{4}$ and 4-nitrophenol and (c) DMPO and $\mathrm{NaBH}_{4}$, respectively. When adding the catalyst in the solution containing DMPO, $\mathrm{NaBH}_{4}$ and 4-nitrophenol, EPR spectrum becomes more complicated (spectrum (a)). By analyzing spectrum (a), we found that not only H-DMPO adducts but also $\mathrm{HOO}^{\circ}$ free radicals formed in the process of catalytic reaction. ${ }^{69}$ The formation of $\mathrm{HOO}^{\circ}$ may be due to a large amount of $\mathrm{H}^{*}$ radicals rapidly produced over the catalyst and trapped by trace amount oxygen in the solution. Besides, control experiments revealed that no $\mathrm{H}^{\cdot}$ adduct formed for 4-nitrophenol or catalysts with and without DMPO (Fig. S9d-h†). According to the EPR results, since the catalytic reaction takes place on the surface of metal, the formation of the hydrogen spin adducts most likely come from the abstraction of hydrogen from the cobalt surface by a spin trap. This is similar to the formation of $\mathrm{Au}-\mathrm{H}$ species during the alcohol oxidation. ${ }^{69}$ These results thus strongly suggest intermediate formation of $\mathrm{Co}-\mathrm{H}$ species during 4nitrophenol reduction.

The kinetics of this reaction has been modeled on the basis of a Langmuir-Hinshelwood mechanism, namely, both reactants need to be adsorbed on the surface prior to reaction. ${ }^{70}$ It means the adsorption of reactants is of great importance for the reaction. In this work, the strong absorption of 4-nitrophenol by h-BN improves local concentration of reactants around the catalyst, which is favorable for the catalytic reaction. This can be regarded as a synergistic effect of the shell h-BN and the core cobalt. On the basis of our results, we propose the following possible mechanism for Co@BN catalyzing 4-nitrophenol reduction in the presence of $\mathrm{NaBH}_{4}$ (Fig. 8a). Firstly, $\mathrm{BH}_{4}{ }^{-}$and 4-nitrophenol are adsorbed on the catalysts surface. Then the adsorbed $\mathrm{BH}_{4}{ }^{-}$transfers electrons to Co NPs to form $\mathrm{Co}-\mathrm{H}$ species. Secondly, the electrons are transferred from $\mathrm{Co}-\mathrm{H}$ species to the adsorbed 4-nitrophenol and thus reduction of 4nitrophenol to 4-aminophenol proceeds. According to the possible reaction pathways for the catalytic reduction of aromatic nitro compounds based on Haber's model, ${ }^{71,72}$ a direct hydrogenation route for 4-nitrophenol could be schematically presented in Fig. 8b. ${ }^{64}$ This is a six-electron transfer process. ${ }^{73}$ Finally, 4-aminophenol is desorbed from the surface of Co@BN catalysts and dispersed in the reaction solution. To gain further insight into the detailed mechanism, however, more experimental and theoretical work is needed. (a)
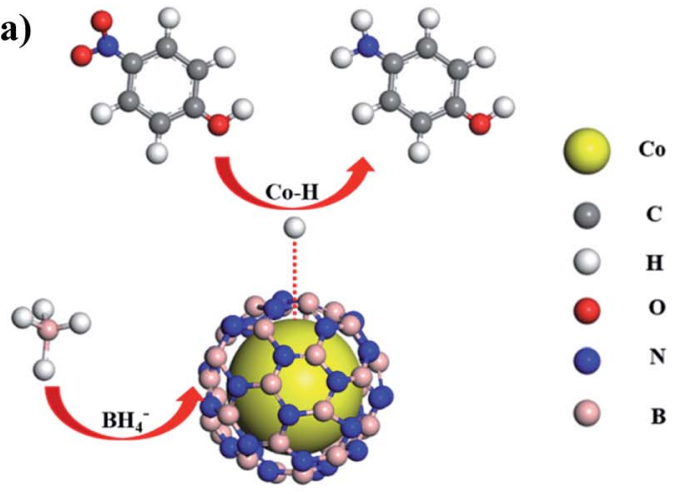

(b)<smiles>C=CC(C)(C)C(=O)[N+]([O-])(O)c1ccc(O)cc1</smiles>

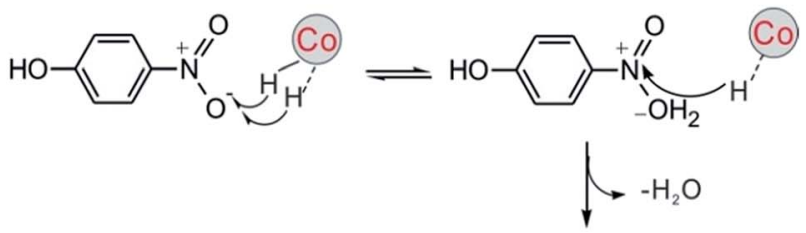<smiles>O=Cc1ccc(NC=C[O+]Nc2ccc(O)cc2)cc1</smiles><smiles>C[C@H](O)c1ccc(O)cc1</smiles>

Fig. 8 (a) Proposed mechanism and (b) possible reaction pathways for the 4-NP reduction by $\mathrm{NaBH}_{4}$ in the presence of a Co@BN catalyst.

\section{Conclusions}

In this study, we present a facile one-step synthesis of Co@BN core-shell nanostructures through high-temperature calcination of boron oxide, urea and cobalt(II) nitrate. The as-prepared Co@BN nanoparticles exhibited high chemical stability and good magnetic properties and were used as catalysts for the reduction of nitroarenes. We found that Co@BN nanoparticles showed high catalytic performance, durable stability and magnetic recyclability for hydrogenation of nitroarenes to aminoarenes in the presence of excess $\mathrm{NaBH}_{4}$. We proved that the sample $13.6 \mathrm{wt} \%$ Co@BN exhibited the excellent catalytic activity in hydrogenation of 4-nitrophenol, 4-nitroaniline, 4nitrochlorobenzene, 4-nitromethylbenzene and 4-nitroanisole. In addition, a significant synergistic effect of the support h-BN was observed by effectively adsorbing the reactant nitroaromatics, leading to an obvious increase in its surface concentration. Furthermore, we also demonstrated that the catalytic reaction is first order with respect to 4-nitrophenol 
concentration, sodium borohydride concentration and catalyst amount. The activation energy for reduction of 4-nitrophenol for $13.6 \mathrm{wt} \% \mathrm{Co@BN}$ was determined to be $102.93 \mathrm{~kJ} \mathrm{~mol}^{-1}$. This work gives evidence that Co@BN core-shell nanoparticles possess easy recyclability, chemical stability and excellent catalytic activity for surface catalytic reaction, and the design concept used in the Co@BN core-shell catalyst can be extended to other metal/nonmetal nanocomposites.

\section{Conflict of interest}

The authors declare no competing financial interest.

\section{Acknowledgements}

This work was supported by the National Natural Science Foundation of China (No. U1662112, 21273038, 21543002 and 11305091).

\section{References}

1 Y. Bao, H. Calderon and K. M. Krishnan, J. Phys. Chem. C, 2007, 111, 1941-1944.

2 O. Margeat, C. Amiens, B. Chaudret, P. Lecante and R. E. Benfield, Chem. Mater., 2005, 17, 107-111.

3 L. Zhou, Y. Guo and K. Hideo, AIChE J., 2014, 60, 2907-2917. 4 F. Hebrard and P. Kalck, Chem. Rev., 2009, 109, 4272-4282.

5 G. Cahiez and A. Moyeux, Chem. Rev., 2010, 110, 1435-1462. 6 S. Gao, Y. Lin, X. Jiao, Y. Sun, Q. Luo, W. Zhang, D. Li, J. Yang and Y. Xie, Nature, 2016, 529, 68-71.

7 A. P. Unnarkat, T. Sridhar, H. Wang, S. Mahajani and A. K. Suresh, AIChE J., 2016, 62, 4384-4402.

8 H. Wang, Z. Dong and C. Na, ACS Sustainable Chem. Eng., 2013, 1, 746-752.

9 Y. Niu and R. M. Crooks, C. R. Chim., 2003, 6, 1049-1059.

10 C. J. Zhong and M. M. Maye, Adv. Mater., 2001, 13, 15071511.

11 E. E. Carpenter, C. Sangregorio and C. J. O'Connor, IEEE Trans. Magn., 1999, 35, 3496-3498.

12 N. S. Sobal, U. Ebels, H. Möhwald and M. Giersig, J. Phys. Chem. B, 2003, 107, 7351-7354.

13 N. S. Sobal, M. Hilgendorff, H. Möhwald and M. Giersig, Nano Lett., 2002, 2, 621-624.

14 M. A. Hines and P. Guyot-Sionnest, J. Phys. Chem. C, 1996, 100, 468-471.

15 B. O. Dabbousi, J. Rodriguez-Viejo, F. V. Mikulec, J. R. Heine, H. Mattoussi, R. Ober, K. F. Jensen and M. G. Bawendi, J. Phys. Chem. B, 1997, 101, 9463-9475.

16 X. Peng, M. C. Schlamp, A. V. Kadavanich and A. P. Alivisatos, J. Am. Chem. Soc., 1997, 119, 7019-7029.

17 O. I. Mićić, B. B. Smith and A. J. Nozik, J. Phys. Chem. B, 2000, 104, 12149-12156.

18 Y. W. Cao and U. Banin, Angew. Chem., Int. Ed., 1999, 38, 3692-3694.

19 M. A. Correa-Duarte, M. Giersig and L. M. Liz-Marzan, Chem. Phys. Lett., 1998, 286, 497-501.
20 M. Danek, K. F. Jensen, C. B. Murray and M. G. Bawendi, Chem. Mater., 1996, 8, 173-180.

21 C. W. Chen, M. Q. Chen, T. Serizawa and M. Akashi, Adv. Mater., 1998, 10, 1122-1126.

22 S. Phadtare, A. Kumar, V. P. Vinod, C. Dash, D. V. Palakar, M. Rao, P. G. Shukla, S. Sivaram and M. Sastry, Chem. Mater., 2003, 15, 1944-1949.

23 S. H. Joo, J. Y. Park, C. K. Tsung, Y. Yamada, P. Yang and G. A. Somorjai, Nat. Mater., 2009, 8, 126-131.

24 H. G. Boyen, G. Kastle, K. Zurn, T. Herzog, F. Weigl, P. Ziemann, O. Mayer, C. Jerome, M. Moller, J. P. Spatz, M. G. Garnier and P. Oelhafen, Adv. Funct. Mater., 2003, 13, 359-364.

25 L. Hang, Y. Zhao, H. Zhang, G. Liu, W. Cai, Y. Li and L. Qu, Acta Mater., 2016, 105, 59-67.

26 A. Lopez-Bezanilla, J. Huang, H. Terrones and B. G. Sumpter, Nano Lett., 2011, 11, 3267-3273.

27 C. Huang, Q. liu, W. Fan and X. Qiu, Sci. Rep., 2015, 5, 16736. 28 L. Song, L. Ci, H. Lu, P. B. Sorokin, C. Jin, J. Ni, A. G. Kvashnin, D. G. Kvashnin, J. Lou, B. I. Yakobson and P. M. Ajayan, Nano Lett., 2010, 10, 3209-3215.

29 Z. Liu, Y. Gong, W. Zhou, L. Ma, J. Yu, J. C. Idrobo, J. Jung, A. H. MacDonald, R. Vajtai, J. Lou and P. M. Ajayan, Nat. Commun., 2013, 4, 2451.

30 W. Lei, D. Portehault, D. Liu, S. Qin and Y. Chen, Nat. Commun., 2013, 4, 1777.

31 Q. Weng, Y. Ide, X. Wang, X. Wang, C. Zhang, X. Jiang, Y. Xue, P. Dai, K. Komaguchi, Y. Bando and D. Golberg, Nano Energy, 2015, 16, 19-27.

32 X. Lv, J. Wang, Z. Yan, D. Jiang and J. Liu, J. Mol. Catal. A: Chem., 2016, 418-419, 146-153.

33 M. Wang, M. Li, L. Xu, L. Wang, Z. Ju, G. Li and Y. Qian, Catal. Sci. Technol., 2011, 1, 1159.

34 G. Yadav and P. Goel, Clean Technol. Environ. Policy, 2002, 4, 227-234.

35 G. D. Yadav, Y. B. Jadhav and S. Sengupta, Chem. Eng. Sci., 2003, 58, 2681-2689.

36 Y. Zhang, H. P. Tran, I. Hussain, Y. Zhong and S. Huang, Chem. Eng. J., 2015, 279, 396-401.

37 Y. Yuan, H. Tao, J. Fan and L. Ma, Chem. Eng. J., 2015, 268, 38-46.

38 Y. Q. Zhang, X. Z. Du and W. L. Huang, Chin. Chem. Lett., 2011, 22, 358-361.

39 T. R. Mandlimath and B. Gopal, J. Mol. Catal. A: Chem., 2011, 350, 9-15.

40 K. L. Wu, X. W. Wei, X. M. Zhou, D. H. Wu, X. W. Liu, Y. Ye and Q. Wang, J. Phys. Chem. C, 2011, 115, 16268-16274.

41 P. Deka, R. C. Deka and P. Bharali, New J. Chem., 2014, 38, 1789.

42 J. Li, C. Y. Liu and Y. Liu, J. Mater. Chem., 2012, 22, 8426.

43 B. A. Donlon, E. Razo-Flores, J. A. Field and G. Lettinga, Appl. Environ. Microbiol., 1995, 61, 3889-3893.

44 M. Guo, J. He, Y. Li, S. Ma and X. Sun, J. Hazard. Mater., 2016, 310, 89-97.

45 S. M. Alshehri, T. Almuqati, N. Almuqati, E. Al-Farraj, N. Alhokbany and T. Ahamad, Carbohydr. Polym., 2016, 151, 135-143. 
46 C. Huang, W. Ye, Q. Liu and X. Qiu, ACS Appl. Mater. Interfaces, 2014, 6, 14469-14476.

47 X. Qiu, Q. Liu, M. Song and C. Huang, J. Colloid Interface Sci., 2016, 477, 131-137.

48 Y. Li, W. Qiu, F. Qin, H. Fang, V. G. Hadjiev, D. Litvinov and J. Bao, J. Phys. Chem. C, 2016, 120, 4511-4516.

49 V. Gandhi, R. Ganesan, H. H. Abdulrahman Syedahamed and M. Thaiyan, J. Phys. Chem. C, 2014, 118, 9715-9725.

50 Q. Yang, Y. Z. Chen, Z. U. Wang, Q. Xu and H. L. Jiang, Chem. Commun., 2015, 51, 10419-10422.

51 X. Chen, J. Chang, H. Yan and D. Xia, J. Phys. Chem. C, 2016, 120, 28912-28916.

52 S. Wunder, F. Polzer, Y. Lu, Y. Mei and M. Ballauff, J. Phys. Chem. C, 2010, 114, 8814-8820.

53 D. T. Dam and J. M. Lee, ACS Appl. Mater. Interfaces, 2014, 6, 20729-20737.

54 L. Gao, R. Li, X. Sui, R. Li, C. Chen and Q. Chen, Environ. Sci. Technol., 2014, 48, 10191-10197.

55 X. Xia, J. Tu, Y. Zhang, X. Wang, C. Gu, X. Zhao and H. Fan, ACS Nano, 2012, 6, 5531-5538.

56 K. Y. Andrew Lin and H. A. Chang, Chem. Eng. J., 2016, 296, 243-251.

57 L. Zhang, W. Wang, L. Zhou, M. Shang and S. Sun, Appl. Catal., B, 2009, 90, 458-462.

58 E. Seo, J. Kim, Y. Hong, Y. S. Kim, D. Lee and B.-S. Kim, J. Phys. Chem. C, 2013, 117, 11686-11693.

59 M. Nemanashi and R. Meijboom, Catal. Commun., 2016, 83, 53-57.
60 A. Noschese, A. Buonerba, P. Canton, S. Milione, C. Capacchione and A. Grassi, J. Catal., 2016, 340, 30-40.

61 H. S. Shin and S. Huh, ACS Appl. Mater. Interfaces, 2012, 4, 6324-6331.

62 A. A. Vernekar, S. Patil, C. Bhat and S. G. Tilve, RSC Adv., 2013, 3, 13243.

63 T. Yang, H. Y. Zou and C. Z. Huang, ACS Appl. Mater. Interfaces, 2015, 7, 15447-15457.

64 F. Xia, X. Xu, X. Li, L. Zhang, L. Zhang, H. Qiu, W. Wang, Y. Liu and J. Gao, Ind. Eng. Chem. Res., 2014, 53, 1057610582.

65 D. Sun, V. Mazumder, Ö. Metin and S. Sun, ACS Catal., 2012, 2, 1290-1295.

66 E. K. Abo-Hamed, T. Pennycook, Y. Vaynzof, C. Toprakcioglu, A. Koutsioubas and O. A. Scherman, Small, 2014, 10, 3145-3152.

67 H. Li, F. Yue, C. Yang, P. Xue, N. Li, Y. Zhang and J. Wang, CrystEngComm, 2017, 19, 64-71.

68 K. Makino, M. M. Mossoba and P. Riesz, J. Phys. Chem., 1983, 87, 1369-1377.

69 M. Conte, H. Miyamura, S. Kobayashi and V. Chechik, J. Am. Chem. Soc., 2009, 131, 7189-7196.

70 S. Wunder, F. Polzer, Y. Lu, Y. Mei and M. Ballauff, J. Phys. Chem. C, 2010, 114, 8814-8820.

71 A. Corma, P. Concepcion and P. Serna, Angew. Chem., 2007, 46, 7266-7269.

72 F. Haber, Z. Elektrochem., 1898, 22, 506.

73 S. Saha, A. Pal, S. Kundu, S. Basu and T. Pal, Langmuir, 2010, 26, 2885-2893. 